\title{
Perceived self-efficacy in the context of teamwork and entrepreneurship in engineering and social sciences college students
}

\author{
Maria Del Carmen Zueck Enriquez, Francisco Muñoz Beltran, Veronica Benavides Pando, \\ Alejandro Chavez Guerrero y, Juan Francisco Aguirre Chavez ${ }^{*}$
}

Faculty of Physical Culture Sciences, Autonomous University of Chihuahua, Chihuahua, México

Email address:

jaguirre@uach.mx (J. F. A. Chavez)

\section{To cite this article:}

Maria Del Carmen Zueck Enriquez, Francisco Muñoz Beltran, Veronica Benavides Pando, Alejandro Chavez Guerrero y, Juan Francisco Aguirre Chavez. Perceived Self-Efficacy in the Context of Teamwork and Entrepreneurship in Engineering and Social Sciences College Students. Psychology and Behavioral Sciences. Vol. 4, No. 1, 2015, pp. 18-22. doi: 10.11648/j.pbs.20150401.13

\begin{abstract}
The purpose of the present study is to compare the profiles of perceived self-efficacy in teamwork and entrepreneurship between Engineering and Social Sciences university students. The total sample consists of 1,181 participants; 592 from the Engineering field and 589 from the Social Sciences programs, with an average age of 18.43 years $(\mathrm{SD}=0.95)$ and 18.38 years $(\mathrm{SD}=0.86)$ respectively. A quantitative approach with a descriptive and transversal survey design was used. All the participants completed the Self-efficacy Teamwork and Entrepreneurship Scale. The results of the one-way multivariate analysis of variance, followed by the one-way univariate analysis of variance, showed that the Social Sciences students reported statistically significant $(p<.05)$ better perceived self-efficacy, desired self-efficacy and reachable self-efficacy in teamwork than the Engineering participants. Regarding the entrepreneurship factor, the Social Sciences students reported statistically significant greater desired and reachable self-efficacy than their Engineering counterparts $(p<.05)$. However, for all the other variables, statistically significant differences were not found $(p>.05)$.
\end{abstract}

Keywords: Student'S Beliefs, Higher Education, Academic Performance, Student Characteristics

\section{Introduction}

Empiric research has broadly demonstrated that selfefficacy is a better academic achievement predictor than other cognitive variables (Bandura, 1982); in addition, it may also forecast future success (Bandura, 1997; Ornelas, Blanco, Gastélum, \& Chávez, 2012), and it represents an important competence and achievement cognitive mediator (Vera, Salanova, \& Martín-del-Río, 2011) for it enhances cognitive processes (Carbonero\& Merino, 2008; Ornelas, Blanco, Rodríguez, \& Flores, 2011).

According to Bandura (1997), people's behavior can better be predicted based on the beliefs individuals have about their own skills rather than by what they can actually do, since these perceptions help outline what people do with their knowledge and abilities (Adeyemo, 2007; H. Blanco, Martínez, Zueck, \&Gastélum, 2011). Such self-perception, known as self-efficacy, deeply influences task and activity choice, the effort and perseverance when in the face of certain challenges, and even the emotional reactions in hardships (Vera et al., 2011). Self-efficacy beliefs definitely represent a cognitive mechanism mediating between knowledge and action, one which determines success, together with other variables (Carbonero\& Merino, 2008; Ornelas et al., 2011).

An example of the importance of self-efficacy is seen in academics when individuals with the same level of skill and knowledge perform differently and/or come up with varying results, in other words, the reason people's performance and skills differ (Bandura, 1982; Pérez et al., 2011). This behavior explains why expected academic achievement also depends on perceived self-efficacy to successfully manage academic demands. Therefore, self-efficacy beliefs in one's own capacities are essential to handle academic work; since students who trust their skills are more motivated to accomplish their goals (Á. Blanco, 2010). On the other hand, 
people who hesitate about their own skills may perceive scenarios as more difficult than they really are; such belief generates tension, depression, and a narrow perspective for problem-solving (Vera et al., 2011). There is evidence to prove that a low self-efficacy level is responsible not only for decreased academic achievement and interest, but it is also related to young people's misfit behavior (Zimmerman \&Kitsantas, 2005). Hence, it is important for education to strengthen the student's academic achievement development and foster the skills that will allow him/her to believe in his/her own abilities (Carbonero\& Merino, 2008; Ornelas et al., 2011).

The present is mainly a descriptive study trying to compare and contrast social sciences and engineering college students' perceived self-efficacy profiles.

The purpose of this applied research is to generate information which will result in a high-quality, educational practice focused on diversity; contributing to the pedagogical realm by defining the elements of an academic performance and an immanent human development model. The study is grounded on the premise that improving the learner's perception of his/her capability is a valuable educational goal, since by potentiating such perception, improvement on academic achievements and self-esteem will follow; thus considering that the continuous awareness of failure diminishes success expectations and in no way fosters neither learning nor personal growth. Hence, this study provides evidence and data that will motivate educational intervention from a classroom-diversity perspective.

\section{Method}

\subsection{Participants and Design}

The sample consists of 1,181 participants, 592 (50.1\%) Engineering students and 589 (49.9\%) Social Sciences students. This was achieved from a convenience sampling trying to cover a representative cross section from bothschools, engineering and social sciences, at the Autonomous University of Chihuahua.

The students sample from Engineering is made up 592 participants; $143(24.2 \%)$ women and 449 (75.8\%) men. Age ranges from 17 to 20 years, with a mean of 18.43 and a standard deviation of 0.95 years.

The Social Sciences student sample is made up 589 participants; 376 (63.8\%) women and 213 (36.2\%) men. Age ragines from 17 to 20 , with a mean of 18.38 and a standard deviation of 0.86 years .

Regarding the design of the study, a quantitative approach with a descriptive and transversal survey design was used (Hernández, Fernández, \& Baptista, 2010).The independent variable was Type of Major (Engineering and Social Sciences students), and the dependent variables were the mean scores in the four scenarios in both teamwork and entrepreneurship.

\subsection{Instrument}

Self-efficacy in teamwork and entrepreneurship was measured by the Self-efficacy Teamwork and Entrepreneurship Scale (Gastélum, Guedea, Viciana, \& Peinado, 2012). This questionnaire consists of a 16-item scale (Table 1) with two subscales: teamwork ( 8 items) and entrepreneurship (8 items). According to previous studies (H. Blanco et al., 2011; Viciana, Cervelló, \& Ramírez, 2007), due to the fact that in the Mexican academic context students are commonly assessed by a scale from 0 to 10 , in the present study, a Likert-type scale from 0 to 10 was chosen. For each domain (item) of the teamwork and entrepreneurship competences (subscales), the participants were asked about how capable they feel, how much interest they have, and if they would make an effort to change, how capable they will be to... Therefore, all the participants responded to each of the 16 items of the questionnaire in the three different scenarios: (a) Scenario of perceived ability, responding in the context "how capable I feel to...to manage in each of the domains of the afore mentioned competences:" (b) Scenario of interest in being able, responding in the context "how much interest I have in being able to... to manage in each of the domains of the competences above mentioned"; and (c) Scenario of change to be able to, responding into the context "if I would make an effort to change, how much capable I will be able to... to manage in each of the domains of the afore mentioned competences."

Table 1. Items of the Self-efficacy Teamwork and Entrepreneurship Scale grouped by factors.

\begin{tabular}{ll}
\hline Factor & Item \\
\hline & 2 Demonstrate capacity of employment and self-employment generation \\
& 4 Ideally take advantage of available resources \\
& 6 Apply strategic management principles in project development \\
& 8 Apply methods that promote, execute, and evaluate a project's impact \\
& 10 Join the academic and work environments \\
12 Create and innovate & 14 Generate and adapt new technologies in my field \\
& 16 Employ basic technology equipment procedures in the operation \\
& 1. Participate in plan and project design and execution through teamwork \\
& 3. Comply and assure compliance with rules and regulations in a social context \\
& 5. Interact in multidisciplinary groups \\
7. Identify entrepreneurship skills and team development potential \\
9. Develop and promote a teamwork culture towards the achievement of a common goal \\
11. Show respect, tolerance, responsibility and openness in confrontation and plurality in team work \\
13. Respect, tolerate, and be flexible when in the face of divergent thinking to achieve consented agreements \\
15 Identify diversity and contribute to personal and team make-up and development
\end{tabular}


When calculating the scores for both dimensions of problem solving and scientific communication, four different values were calculated: (1) Perceivedself-efficacy, obtained from the average scores in the scenario of perceived ability; (2) Desired self-efficacy, calculated from the average scores in the scenario of interest of being able; (3) Reachable selfefficacy, obtained from the mean scores in the scenario of being able; and (4) Possibility of improvement in the perceived self-efficacy, calculated from the mean difference between reachable self-efficacy and perceived self-efficacy. A higher score indicates greater self-efficacy, whereas a lower score represents lesser self-determination. The Selfefficacy Teamwork and Entrepreneurship Scale demonstrated adequate psychometric properties (GFI $=.859$; RMSEA $=.096$; Cronbach coefficient alphas $=.916$ and .932 for teamwork and entrepreneurship, respectively) (Gastélum et al., 2012).

\subsection{Procedure}

Engineering and Social Sciences freshman students at the Autonomous University of Chihuahua were invited to participate in the present study. These university students were fully informed about all the features of the project. Then, all the students that had agreed to participate were asked to sign a written informed consent. After the students' approvals were obtained, participants completed the afore mentioned questionnaire by means of the instrument module administrator of the Scales Editor Version 2.0(H. Blanco et al., 2013).

Participants completed the questionnaire in the computer labs at their schools during a class meeting. At the beginning of the session, the researchers gave a general introduction about the importance of the research and how to access the questionnaire through the software. When the participants were in the editor, the instructions about how to fill out the questionnaire correctly appeared before the instrument. Additionally, the participants were advised to ask for help if confused concerning either the instructions or the clarity of a particular item. Completion of the entire questionnaire took approximately 30 minutes. At the end of the session their participation was welcomed. Afterwards, when all the participants had completed the questionnaire, the data were collected by means of the results generator module of the Scales Editor Version 2.0(H. Blanco et al., 2013).

\subsection{Data Analysis}

Descriptive statistics (means and standard deviations) for all the variables were calculated. Subsequently, after verifying that the data met the assumptions of parametric statistical analyses, a one-way multivariate analysis of variance (MANOVA), followed by the one-way univariate analysis of variance (ANOVA), were used to examine the differences between the Social Sciences and Engineering students in both the reported self-efficacy in teamwork and entrepreneurship scores. Moreover, the effect size was estimated using the eta-squared $\left(\eta^{2}\right)$. The internal consistency reliability of the each variable was estimated using the Cronbach coefficient alphas (ICC) and the 95\% confidence intervals (CI). All statistical analyses were performed using the SPSS version 20.0 for Windows $\left(\right.$ IBM ${ }^{\circledR}$ SPSS ${ }^{\circledR}$ Statistics 20).The statistical significance level was set at $p<.05$.

\section{Results}

\subsection{Teamwork Factor}

Table 2 shows the means and standard deviations for selfefficacy in the team work factor, as well as the MANOVA and subsequent ANOVAs results. MANOVA numbers show significant global differences on the self-efficacy scores for team work in the major variable, i.e., Engineering and Social Sciences (Wilks' $\lambda=.984 ; \mathrm{p}=<.001 ; \eta 2=.016$ ). Later, ANOVAs report that Social Sciences students have a higher perceived self-efficacy $(\mathrm{F} 1=12.165, \mathrm{p}<.01)$, desired selfefficacy $(\mathrm{F} 1=15.994, \mathrm{p}<.001)$, and reachable self-efficacy $(\mathrm{F} 1=18.912, \mathrm{p}<.001)$ than their Engineering counterparts. There are no significant differences in the possibility of improvement of their perceived self-efficacy between both groups ( $>$ $>05)$. Finally, the team work factor inner consistency (reliability) scored quite high: perceived selfefficacy .912 (.904-.919), desired self-efficacy .928 (.922$.934)$, and reachable self-efficacy .933 (.927-.939).

Table 2. MANOVA results for the type of major differences in the four variables of self-efficacy for teamwork.

\begin{tabular}{|c|c|c|c|c|c|}
\hline & Social Sciences $(n=589)$ & Engineering $(n=592)$ & $F$ & $p$ & $\overline{\eta^{2}}$ \\
\hline & & & 6.462 & $<.001$ & .016 \\
\hline Perceived self-efficacy & $8.08(1.21)$ & $7.82(1.30)$ & 12.165 & $<.01$ & .010 \\
\hline Desired self-efficacy & $8.89(1.08)$ & $8.61(1.28)$ & 15.994 & $<.001$ & .013 \\
\hline Reachable self-efficacy & $9.12(0.92)$ & $8.86(1.14)$ & 18.912 & $<.001$ & .016 \\
\hline Possibility for improving perceived self-efficacy & $1.04(0.79)$ & $1.03(0.78)$ & 0.024 & .876 & .000 \\
\hline
\end{tabular}

Note. Descriptive values are reported as mean (standard deviation).

\subsection{Entrepreneurship Factor}

Table 3 presents mean and standard deviation values for perceived self-efficacy in the entrepreneurship factor, including the MANOVA and subsequent ANOVAs results. MANOVA values indicate significant global differences in the major variable, i.e. Engineering and Social Sciences majors, in the entrepreneurship factor self-efficacy scores (Wilks' $\lambda=.992 ; \mathrm{p}=<.05 ; \eta 2=.008$ ). Furthermore, ANOVAs results indicate that Social Sciences majors report a higher desired self-efficacy $(\mathrm{F} 1=3.841, \mathrm{p}<.05)$ and reachable self-efficacy $(\mathrm{F} 1=8.159, \mathrm{p}<.01)$ than their 
Engineering counterparts. There were no significant differences $(p>.05)$ in the perceived self-efficacy and possibility for improving perceived-self-efficacy variables. Finally, the entrepreneurship factor inner consistency (reliability) scored quite high: perceived self-efficacy .923 (.916-.929), desired self-efficacy .932 (.926-.938), and reachable self-efficacy .937 (.931-.942).

Table 3. MANOVA results for the type of major differences in the four variables of self-efficacy for entrepreneurship.

\begin{tabular}{|c|c|c|c|c|c|}
\hline & Social Sciences $(n=589)$ & Engineering $(n=592)$ & $F$ & $p$ & $\eta^{2}$ \\
\hline & & & 3.279 & $<.05$ & .008 \\
\hline Perceived self-efficacy & $7.90(1.31)$ & $7.80(1.32)$ & 1.601 & .206 & .000 \\
\hline Desired self-efficacy & $8.89(1.07)$ & $8.76(1.23)$ & 3.841 & $<.05$ & .003 \\
\hline Possibility for improving perceived self-efficacy & $1.19(0.91)$ & $1.12(0.85)$ & 1.955 & .162 & .000 \\
\hline
\end{tabular}

Note. Descriptive values are reported as mean (standard deviation).

\section{Discussion}

In the team work factor, Social Sciences majors perceive themselves as more self-efficient and with a greater possibility and need of being self-efficient than the Engineering majors in the following items: being able to respect, tolerate, and be flexible when in the face of divergent thinking to achieve consented agreements; interact in multidisciplinary groups; identify entrepreneurship skills and team development potential; and participate in plan and project design and execution through teamwork.

Furthermore, in the entrepreneurship factor, once more, Social Sciences majors perceive themselves with a greater possibility and need of being more self-efficient than their Engineering counterparts in the following items: being able to demonstrate capacity of employment and self-employment generation; link the academic and work environments; create and innovate; ideally take advantage of available resources; and apply strategic management principles in project development.

On the other hand, when comparing the self-efficacy profiles of participants from both academic fields, even though there are significant differences, the degree is quite small to be considered. Hence, it may be argued that perceived selfefficacy regarding both team work and entrepreneurship factors is balanced. This result agrees with a similar college student, perceived self-efficacy study authored by Ornelas, Blanco, Peinado, and Blanco (2012); thus, pointing out an encouraging view of the fact that both Engineering and Social Sciences programs enroll students with the "same quality degree", at least when it comes to self-efficacy.

In addition, the fact that the perceived, desired, and reachable self-efficacy profiles correspond, i.e. the higher the degree of perceived self-efficacy, the greater the wish and possibilities of being efficient, gives ground to conclude that if any self-efficacy profile improves, the other profiles will be enhanced as a result.

Finally, taking into consideration that empiric research has broadly demonstrated that self-efficacy is a better academic achievement predictor than other cognitive variables (Bandura, 1982), which foretells forthcoming success (Bandura, 1997; Ornelas, Blanco, Gastélum, et al., 2012), and that it is an important cognitive mediator between competence and achievement (Vera et al., 2011) since it enhances cognitive processes (Carbonero\& Merino, 2008; Ornelas et al., 2011), we conclude that improving learners' perceived self-efficacy is a fundamental educational goal because there is the possibility that once perceived selfefficacy is fostered, academic achievement and self-esteem enhancement will follow. On the other hand, continuous failure awareness minimizes success expectations and by no means favors neither learning nor personal growth.

Moreover, we emphasize the need for further research on the subject of self-efficacy in México since most studies on the topic have been developed in other countries.

\section{Acknowledgements}

This study is part of a project funded by the Secretaría de Educación Pública-Subsecretaría de Educación SuperiorDirección General de Educación Superior Universitaria de México [Mexican Ministry of Education-Department of Higher Education-General Directorate of the University Education] (OF-13-6894).

\section{References}

[1] Adeyemo, D. A. (2007). Moderating Influence of Emotional Intelligence on the Link Between Academic Self-efficacy and Achievement of University Students. Psychology Developing Societies, 19(2), 199-213.

[2] Bandura, A. (1982). Self-efficacy mechanism inhuman agency. American Psychologist, 37(2), 122-147.

[3] Bandura, A. (1997). Self-efficacy: The exercise of Control. New York: Freeman.

[4] Blanco, Á. (2010). Creencias de autoeficacia de estudiantes universitarios: un estudio empírico sobre la especificidad del constructo. RELIEVE, 16(1), 1-28.

[5] Blanco, H., Martínez, M., Zueck, M. d. C., \& Gastélum, G. (2011). Análisis psicométrico de la escala autoeficacia en conductas académicas en universitarios de primer ingreso. Actualidades Investigativas en Educación, 11(3), 1-27.

[6] Blanco, H., Ornelas, M., Tristán, J. L., Cocca, A., MayorgaVega, D., López-Walle, J., \& Viciana, J. (2013). Editor for creating and applying computerise surveys. Procedia Social and Behavioral Sciences, 106, 935-940. doi: http://dx.doi.org/10.1016/j.sbspro.2013.12.105 
[7] Carbonero, M. Á., \& Merino, E. (2008). Autoeficacia y madurez vocacional. Psicothema, 16(2), 229-234.

[8] Gastélum, G., Guedea, J. C., Viciana, J., \& Peinado, J. E. (2012). Composición Factorial de una Escala de Autoeficacia en el Ámbito del Trabajo en Equipo y Liderazgo en Universitarios de Ciencias de la Salud. Formación Universitaria, 5(4), 49-60. doi: $10.4067 / \mathrm{S} 0718$ 50062012000400006

[9] Hernández, R., Fernández, C., \& Baptista, P. (2010). Metodología de la investigación. México: McGraw- Hill.

[10] Ornelas, M., Blanco, H., Gastélum, G., \& Chávez, A. (2012). Autoeficacia Percibida en la conducta Académica de Estudiantes Universitarias. Formación Universitaria, 5(2), 1726.

[11] Ornelas, M., Blanco, H., Peinado, J. E., \& Blanco, J. R. (2012). Autoeficacia percibida en conductas académicas en universitarios. Un estudio respecto a alumnos de Educación Física. Revista Mexicana de Investigación Educativa, 17(54), 779-791.
[12] Ornelas, M., Blanco, H., Rodríguez, J. M., \& Flores, F. J. (2011). Análisis psicométrico de la escala autoeficacia en conductas de cuidado de la salud física en universitarios de primer ingreso. Formación Universitaria, 4(6), 21-34.

[13] Pérez, E., Lescano, C., Heredia, D., Zalazar, P., Furlám, L., \& Martínez, M. (2011). Desarrollo y análisis psicométricos de un inventario de autoeficacia para inteligencias múltiples en niños argentinos Psicoperspectivas, 10(1), 169-189.

[14] Vera, M., Salanova, M., \& Martín-del-Río, B. (2011). Selfefficacy among university faculty: how to develop an adjusted scale. Anales de Psicología, 27(3), 800-807.

[15] Viciana, J., Cervelló, E. M., \& Ramírez, J. (2007). Effects of manipulating positive and negative feedback on goal orientation, perceived motivational climate, satisfaction, task choice, perception of ability, and attitude to physical education lessons. Perceptual and motor skills, 105(1), 67-82.

[16] Zimmerman, B., \& Kitsantas, A. (2005). Homework practice and academic achievement. The mediating role of selfefficacy and perceived responsibility beliefs. Contemporary Educational Psychology, 30(4), 397-417. 